\title{
Developing a Job Description for Assistant Nurses at Assuit University Hospitals
}

\author{
Ebtisam A. Saber, Hala R. Yousef, \& Nahed S. Abo El-Magd
}

Demonstrator in Nursing Administration Department, Faculty of Nursing, Assuit University. Assist. Prof of Nursing Administration, Faculty of Nursing, Assiut University. Lecturer of Nursing Administration, Faculty of Nursing, Assiut University.

\begin{abstract}
Back ground: Health Care Assistants (HCA) emerged primarily to support the professional nurse and to undertake non-nursing duties under the supervision of qualified nurses. Recently unlicensed personnel have been used as substitutes for professional nurses. Aim of the study: To develop a job description for assistant nurses. Setting: The study was carried out at Assuit University Hospitals. Subjects and methods: The subjects included all head nurses working in the designated settings $(n=72)$ and $10 \%$ of the total assistant nurses $(n=40)$. Data collection tools: The data for the present study was collected using three different tools: a questionnaire sheet, an observation sheet (job analysis) and focus group discussion. Results: The present study revealed that there is no training program and orientation made for assistant nurses and there is no job description for them. There was congruency between the head nurses' opinions, job analysis and focus group discussion as regards indirect care, and environmental activities performed by assistant nurses. Recommendations: The researchers recommended a conduct training program for assistant nurses about infection control principles, communication skills, and nursing profession .Constant direct supervision by authoritative persons for assistant nurses should be established in the hospitals.
\end{abstract}

\section{Keywords: Assistant Nurses, Job Analysis \& Job Description.}

\section{Introduction}

Today's health sector faces the challenge of providing high quality care within the context of increasing health care costs and limited resources. Also, staff shortages and the need for cost effectiveness have led to an increasing reliance on health care assistants (Houser, 2003).

The role of the (HCA) emerged primarily to support the professional nurse and to undertake perceived non-nursing duties under the direction and supervision of qualified nurses. They are employed in a variety of settings and carry out a range of tasks and procedures. While they represent a substantial proportion of the health care workforce, the growth of their role has taken place without regulation, clear boundaries, or systematic education and training (Huge, 2004).

New York State Nurses Association (NYSNA) (2007) mentioned that unlicensed assistive personnel (UAPs) assist licensed nurses with non-nursing functions and delivering direct care to patients. Nonnursing functions are generally classified as housekeeping, clerical, transportation, and dietary tasks. Direct patient care activities are not within the legally protected scope of nursing practice and can be assigned to (UAPs) who have demonstrated competency. These activities do not require professional judgment or critical thinking and can be completed using a standard procedure .Yet a nursing assistant's cleaning duties can include emptying garbage cans, ensuring that a patient has clean sheets and towels, and cleaning the floor.
A job description is an organized factual statement of job contents in the form of duties and responsibilities of a specific job, and the preparation of a job description is very important before a vacancy is advertised. It tells in brief the nature and type of job. This type of document is descriptive in nature and includes the following: title/ designation of job and location, the nature of duties and operations to be performed in that job, the nature of authorityresponsibility relationships, necessary qualifications that are required for the job, the relationship of that job with other jobs, and the provision of physical and working conditions or the work environment required for the performance of that job (Management study guide, 2012).

Also, a job description is a management tool that can greatly simplify an organization's human resource management, clarifies work functions and reporting relationships, helps employees understand their jobs, and aids in maintaining a consistent salary structure and performance evaluations (HR-Guide, 2009).

A job description is a product of a job analysis, work interdependent of one another. Job analysis and description are vital because they help to support several human resource management activities such as recruitment and selection processes, compensation, training, and performance appraisals (Williams, 2012).

Significance of the study

An increasing number of assistant nurses were employed at Assiut University Hospitals $(n=450)$ to support nurses in performing non-nursing activities in 
order to free them for direct patient care. It was observed that some of them perform nursing activities that can affect the quality of patient care due to the potential risk to patients, in addition to the absence of a job description, that leads to workplace confusion, and makes them don't know what is expected from them. For these reasons the researchers felt it was necessary to carry out this study to develop a job description for them.

\section{Aims of the study}

The present study aims to

Develop a job description for assistant nurses at Assuit university Hospitals through:

a- Analyzing the job duties and responsibilities of the assistant nurses.

b- Identifying head nurses' opinions about assistant nurses' duties and responsibilities.

c. Conducting a focus group discussion with assistant nurses to answer questions related to their role.

\section{Research questions}

1-What are the requirements, job duties and responsibilities of assistant nurses?

2- Is there a congruency between head nurses' opinions, job analysis and the focus group discussion as regards direct care, indirect care, and environmental activities performed by assistant nurses?

\section{Subjects and methods}

\section{Research design}

A quantitative (cross-sectional) and qualitative (focus group) study design was utilized in the present study.

\section{Study setting:}

The present study was conducted at Assuit University Hospitals; namely, Main Hospital, Woman's Health Hospital and Pediatric Health Hospital.

\section{Study subjects}

The subjects of this study consisted of two categories:

1. All head nurses working in the designated settings $(n=72)$.

2. $10 \%$ of the total number of assistant nurses ( $n=400)$ working at Assuit University Hospitals. The actual number was (40) chosen randomly, classified into two groups : (20) included in the direct observation and (20) participated in the focus group discussions.

\section{Study tools}

The data for the present study were collected by using three different tools; namely:

Tool (1): Questionnaire sheet

This tool consisted of two parts:
Part I: Socio-demographic data sheet of head nurses and assistant nurses

It was used to gather data about age, gender, work setting, educational qualification, and years of experience.

Part II: Assistant nurses' job requirement, duties and responsibilities sheet:

It was developed by the researchers based on related literature. (Spilsbury and Meyer, 2004) and (Ministry of Health, 2009). It was used to determine head nurses' opinions regarding the educational and training requirements, duties and responsibilities of assistant nurses. It consisted of (45) statements covering the following four items: The educational and training requirements (4), direct care activities (19), indirect care activities (13) and environmental activities (9). Each statement was scored one if it had a response or zero if it didn't have a response.

Part III: This part includes an open-ended question about the extra duties which may be performed by assistant nurses in the departments.

Parts II and III were filled by head nurses.

Tool (2): Observation sheet:

It is a standardized record developed by Darbyshire (1969). It included the names of the personnel observed, unit, time, date, a brief description of the activities and remarks. The researchers used direct observation to analyze the job duties and responsibilities performed by assistant nurses.

Tool (3) The Focus Group Discussion:

An interview guide was designed in the Arabic language to obtain in-depth information about assistant nurses' job duties and responsibilities. The

(FGDs) guide included the following questions

1. What are the direct care activities you perform for patients?

2. What are the indirect care activities you perform for patients?

3. What are the environmental activities you perform?

4. Who is responsible for supervising you?

5. What is the formal and informal training program you received after appointment?

6. What is your job description?

7. What are the skills needed for you at the job?

8. What are the problems you face in your job and how can you solve them?

9. What are your suggestions for improving your job?

2. Administrative design

An official permission was obtained from the dean of the Faculty of Nursing, Assiut University, Assiut University hospitals directors, directors of nursing administration departments and the heads of the selected units at (the Main Hospital, Woman's Health Hospital and Pediatric Health Hospital). 


\section{Operational design}

\section{A) Preparatory phase}

This phase took about three months from April to July 2012. After reviewing available literature and studies related to the study topic, the study tools were developed.

The developed questionnaire was tested for its content validity through a jury of experts in the study field including seven nursing faculty members.

The developed job description was examined by a jury involving the matron, four supervisors, and four senior head nurses.

\section{B) Pilot Study}

A pilot study was carried out on $10 \%$ of the study sample chosen randomly to test the clarity, feasibility and relevance of the head nurse questionnaire sheet and necessary modifications were made prior to the actual data collection to make it clear to the participants. Subjects included in the pilot study were excluded from study sample.

\section{C) Field work}

The researcher explained the purpose of the study for each participant. After obtaining oral consent, the study tool was administered to the participants to fill it in. Two students were chosen from Assuit Nursing Technical Institute to assist the researchers in conducting the job analysis (direct observation). The researchers trained them on how collect data. A financial payment was given to the students by the researchers during the period of data collection.

The job analysis record was filled through direct observation and each activity performed by each assistant nurse was recorded every 15 minutes for six successive working days covering the six hours of the morning shift from 7:30 A.M to 1:30 P.M. This phase took about 10 weeks from the second week of July to September 2012.
Structured Focus Group Discussions (FGDs) were held with four groups of assistant nurses at the break time in the evening shift which did not interfere with the work duties. Each group consisted of 5 participants. Invitations were extended to the assistant nurses in each session and an oral consent was taken with an explanation of the purpose of the study. Physical environment was prepared prior to the session to ensure that each group member was physically comfortable as much as possible. The researchers asked the questions openly, motivating the participants to talk about their experience, feeling, and their own opinion. During the sessions a note taker wrote the answers in details and a tape recorder was used. The period of each session was about (30-45 minute). This phase took about one month from the third week of January to the third week of February 2013.

\section{D) Ethical considerations}

The study proposal was approved by the ethical committee at the Faculty of Nursing, Assiut University. The study subjects have an ethical right to participate or refuse participation in the study. An oral agreement from participants was taken.

\section{4-Statistical design}

Data entry and analysis were done using SPSS version 16 (Statistical Package) for Social Science. Quantitative data related to the head nurse's opinionnaire sheet and job analysis observation sheet were presented using descriptive statistics in the form of frequencies, percentages, mean, and chi square, and $P$ value.

Data obtained from the (FGDs) were translated into English by the researchers. Coded materials were compared and organized into themes that were then grouped into central categories. The information in each (FGD) was summarized and grouped according to these predefined information categories.

\section{Results}

Table (1): Socio demographic characteristics of the studied head nurses at Assiut University Hospitals (No=72).

\begin{tabular}{|l|c|c|}
\hline \multicolumn{1}{|c|}{ Items } & (No=72) & $(\%)$ \\
\hline Age & 3 & 4.2 \\
\hline$<25$ years & 24 & 33.3 \\
\hline $25-<30$ & 28 & $\mathbf{3 8 . 8}$ \\
\hline $30-<35$ & 17 & 23.7 \\
\hline$\geq 35$ years & \multicolumn{2}{|c|}{37} \\
\hline Mean & 72 & 100 \\
\hline Gender & \multicolumn{2}{|c|}{1} \\
\hline Female & 72 & \\
\hline
\end{tabular}




\begin{tabular}{|c|c|c|}
\hline Items & $(\mathrm{No}=72)$ & $(\%)$ \\
\hline \multicolumn{3}{|l|}{ Years of experience } \\
\hline$<5$ & 3 & 4.2 \\
\hline $5-<10$ & 28 & 38.8 \\
\hline $10-<15$ & 23 & 31.9 \\
\hline$\geq 15$ & 18 & 25.1 \\
\hline Mean & \multicolumn{2}{|c|}{14.9} \\
\hline \multicolumn{3}{|l|}{ Educational level } \\
\hline Secondary nursing school(diploma) & 9 & 12.5 \\
\hline Bachelor degree of nursing science. & 63 & 87.5 \\
\hline \multicolumn{3}{|l|}{ Setting } \\
\hline Main hospital & 55 & 76.4 \\
\hline Pediatric hospital & 10 & 13.9 \\
\hline Women health hospital & 7 & 9.7 \\
\hline
\end{tabular}

Table (2): Socio demographic characteristics of the studied assistant nurses at Assiut University Hospitals (No=40).

\begin{tabular}{|c|c|c|}
\hline Items & $(\mathrm{No}=40)$ & $(\%)$ \\
\hline \multicolumn{3}{|l|}{ Age } \\
\hline$<20$ years & 8 & 20 \\
\hline $20-<25$ & 14 & 35 \\
\hline $25-<30$ & 11 & 27.5 \\
\hline$\geq 30$ years & 7 & 17.5 \\
\hline Mean & \multicolumn{2}{|c|}{23.6} \\
\hline \multicolumn{3}{|l|}{ Gender } \\
\hline Female & 40 & 100 \\
\hline \multicolumn{3}{|l|}{ Years of experience } \\
\hline$<1$ & 9 & 22.5 \\
\hline $1-<3$ & 11 & 27.5 \\
\hline $3-<5$ & 14 & 35 \\
\hline$\geq 5$ & 6 & 15 \\
\hline Mean & \multicolumn{2}{|c|}{3.2} \\
\hline \multicolumn{3}{|l|}{ Setting } \\
\hline Main hospital & 26 & 65 \\
\hline Pediatric hospital & 7 & 17.5 \\
\hline Women health hospital & 7 & 17.5 \\
\hline \multicolumn{3}{|l|}{ Educational level } \\
\hline Preparatory education & 8 & 20 \\
\hline secondary education(diploma) & 31 & $\mathbf{7 7 . 5}$ \\
\hline Bachelor degree & 1 & 2.5 \\
\hline
\end{tabular}

Table (3): Direct care activities performed by the studied assistant nurses as reported by the head nurses at Assiut University Hospitals (No=72).

\section{Direct care activities}

\begin{tabular}{|c|c|c|c|c|c|}
\hline 1 & Assist in the movement of patients to other departments. & 44 & 61 & 28 & 39 \\
\hline 2 & Help patients to move within the department. & 39 & 54 & 33 & 46 \\
\hline 3 & Help patients to transfer outside the department. & 28 & 38.9 & 44 & 61.1 \\
\hline 4 & Help the nurse in changing position for patient. & 46 & 63.9 & 26 & 36.1 \\
\hline 5 & Assist in patient's general hygiene. & 48 & 66.7 & 24 & 33.3 \\
\hline
\end{tabular}




\begin{tabular}{|c|c|c|c|c|c|}
\hline \multirow{2}{*}{\multicolumn{2}{|c|}{ Direct care activities }} & \multicolumn{4}{|c|}{ No $=72$} \\
\hline & & \multicolumn{2}{|c|}{ Done } & \multicolumn{2}{|c|}{ Not Done } \\
\hline & & \multirow{2}{*}{$\begin{array}{l}\text { No } \\
28 \\
\end{array}$} & \multirow{2}{*}{$\frac{\%}{38.9}$} & \multirow{2}{*}{ No } & \multirow{2}{*}{$\frac{\%}{61.1}$} \\
\hline 6 & Assist in patient bed bath. & & & & \\
\hline 7 & Assist in patient bath inside the bathroom. & 9 & 12.5 & 63 & 87.5 \\
\hline 8 & Handling bedpan for patients who are unable to move. & 16 & 22.2 & 56 & 77.8 \\
\hline 9 & Empty bedpan. & 5 & 6.9 & 67 & 93.1 \\
\hline 10 & Empty urine bag. & 7 & 9.7 & 65 & 90.3 \\
\hline 11 & Determine urine volume in the urine bag. & 21 & 29.2 & 51 & 70.8 \\
\hline 12 & Implementing preparatory enema. & 18 & 25 & 54 & 75 \\
\hline 13 & $\begin{array}{l}\text { Assist during medical examinations of the patients. (Such as } \\
\text { handling things during the examination). }\end{array}$ & 61 & 84.7 & 11 & 15.3 \\
\hline 14 & $\begin{array}{l}\text { Help in preparing patients for operations. (Such as preparing } \\
\text { shaving tools or bathroom). }\end{array}$ & 22 & 30.6 & 50 & 64.4 \\
\hline 15 & Measuring the weight of patients. & 31 & 43 & 41 & 57 \\
\hline 16 & Measuring the length of patients. & 27 & 37.5 & 45 & 62.5 \\
\hline 17 & Help in patient feeding. & 27 & 37.5 & 45 & 62.5 \\
\hline 18 & Make cold compresses for feverish patient. & 28 & 38.9 & 44 & 61.1 \\
\hline 19 & Help the nurse in performing urinary catheterization procedure. & 38 & 52.8 & 34 & 47.2 \\
\hline \multicolumn{2}{|r|}{ P-value } & \multicolumn{4}{|c|}{$(0.000) * *$} \\
\hline
\end{tabular}

Table (4): Indirect care activities performed by the studied assistant nurses as reported by the head nurses at Assiut University Hospitals (No=72).

\begin{tabular}{|c|c|c|c|c|c|}
\hline & \multirow{3}{*}{ Indirect care activities } & \multicolumn{4}{|c|}{$\mathrm{No}=72$} \\
\hline & & \multicolumn{2}{|c|}{ Done } & \multicolumn{2}{|c|}{ Not Done } \\
\hline & & No & $\%$ & No & $\%$ \\
\hline 1 & Sending medical instruments for sterilization. & 61 & 84.7 & 11 & 15.3 \\
\hline 2 & $\begin{array}{l}\text { Bringing machines and medical instruments to the department after } \\
\text { sterilization. }\end{array}$ & 50 & 69.4 & 22 & 30.6 \\
\hline 3 & Cutting gauze and cotton to prepare dressing. & 62 & 86.1 & 10 & 13.9 \\
\hline 4 & Rolling the pads for dressing sterilization. & 62 & 86.1 & 10 & 13.9 \\
\hline 5 & Collecting the specimens and delivering it to the laboratory. & 71 & 98.6 & 1 & 1.4 \\
\hline 6 & Receiving of test results and keeping it in the patient files. & 69 & 95.8 & 3 & 4.2 \\
\hline 7 & Bringing medication requisition with the nurse. & 40 & 55.6 & 32 & 44.4 \\
\hline 8 & Delivering and receiving of correspondence to and from the department. & 47 & 65.3 & 25 & 34.7 \\
\hline 9 & Finishing the process of patient admission. & 16 & 22.2 & 56 & 77.8 \\
\hline 10 & Finishing the patient file and records after death. & 16 & 22.2 & 56 & 77.8 \\
\hline 11 & Finishing records of the nursing team vacations. & 45 & 62.5 & 27 & 37.5 \\
\hline 12 & Delivering patients files to the census office. & 42 & 58.3 & 30 & 41.7 \\
\hline 13 & Answering the department telephone calls. & 50 & 69.4 & 22 & 30.6 \\
\hline \multicolumn{2}{|r|}{ P-value } & \multicolumn{4}{|c|}{$(0.030)^{*}$} \\
\hline
\end{tabular}

\footnotetext{
*statistical significant at $(P \leq 0.05) \quad X^{2}$ test
} 
Table (5) Environmental activities performed by the studied assistant nurses as reported by the head nurses at Assiut University Hospitals (No=72).

\begin{tabular}{|c|c|c|c|c|c|}
\hline & \multirow{3}{*}{ Environmental activities } & \multicolumn{4}{|c|}{ No $=72$} \\
\hline & & \multicolumn{2}{|c|}{ Done } & \multicolumn{2}{|c|}{ Not Done } \\
\hline & & No & $\%$ & No & $\%$ \\
\hline 1 & Help the nurse in making bed correctly. & 67 & 93 & 5 & 7 \\
\hline 2 & Maintain the cleanliness of the surrounding environment. & 60 & 83.3 & 12 & 16.7 \\
\hline 3 & Arrange patient rooms. & 54 & 75 & 18 & 25 \\
\hline 4 & Clean patient's cupboard. & 46 & 63.9 & 26 & 36.1 \\
\hline 5 & Clean patient beds. & 53 & 73.6 & 19 & 26.4 \\
\hline 6 & Cleaning machines and medical instruments. & 62 & 86.1 & 10 & 13.2 \\
\hline 7 & Cleaning medication cart. & 60 & $\mathbf{8 3 . 3}$ & 12 & 16.7 \\
\hline 8 & Arranging medication cart. & 53 & 73.6 & 19 & 26.4 \\
\hline 9 & Arranging supplies cupboard. & 39 & 54.2 & 33 & 45.8 \\
\hline & P-value & \multicolumn{4}{|c|}{$(0.000)^{* * *}$} \\
\hline
\end{tabular}

Table (6): Direct care activities performed by the studied assistant nurses as observed by the researcher at Assiut University Hospitals (No=20).

\begin{tabular}{|c|c|c|c|}
\hline & Direct care activities & $\mathrm{No}=\mathbf{2 0}$ & $\%$ \\
\hline 1 & Measuring vital signs. & 8 & 40 \\
\hline 2 & Applying cold compress for feverish patients. & 2 & 10 \\
\hline 3 & Accompany the patient to the bath room. & 2 & 10 \\
\hline 4 & Helping patient take shower. & 2 & 10 \\
\hline 5 & Helping patient to wear clothes. & 2 & 10 \\
\hline 6 & Performing urine test for Albumin at the unit. & 1 & 5 \\
\hline 7 & Accompanying patients when transferring to other departments. & 3 & 15 \\
\hline 8 & Applying O2 therapy. & 3 & 15 \\
\hline 9 & Applying bronchodilator inhalation cession. & 2 & 10 \\
\hline 10 & Inserting urinary catheter for children. & 1 & 5 \\
\hline 11 & Preparing bottle feeding. & 1 & 5 \\
\hline 12 & Monitoring blood glucose level. & 4 & 20 \\
\hline 13 & Inserting cannula. & 2 & 10 \\
\hline 14 & Applying I. V solutions to cannula. & 6 & 30 \\
\hline 15 & Taking blood samples from patients. & 7 & 35 \\
\hline 16 & Accompanying the patient during medical requests. & 12 & 60 \\
\hline 17 & Preparing equipment for taking blood samples from patient. & 18 & 90 \\
\hline 18 & Preparing equipment for cannula insertion. & 8 & 40 \\
\hline 19 & Preparing for dressing. & 4 & 20 \\
\hline
\end{tabular}

Table (7) Indirect care activities performed by the studied assistant nurses as observed by the researcher at Assiut University Hospitals (No=20).

\begin{tabular}{|c|l|c|c|}
\hline & \multicolumn{1}{|c|}{ Indirect care activities } & No=20 & \% \\
\hline 1 & Oral shift reporting. & 3 & 15 \\
\hline 2 & Collecting, labeling, and sending the specimens to the laboratory. & 18 & 90 \\
\hline 3 & Receiving test results and keeping it in the patient files. & 18 & 90 \\
\hline 4 & Checking patient tests for completeness. & 18 & 90 \\
\hline 5 & Prepare dressing sterilization. & 20 & 100 \\
\hline 6 & Sending medical instruments for sterilization. & 11 & 55 \\
\hline 7 & Bringing medical instruments to the department after sterilization. & 11 & 55 \\
\hline 8 & Bringing medication from the pharmacy with the responsible nurse. & 8 & 40 \\
\hline
\end{tabular}




\begin{tabular}{|c|l|c|c|}
\hline \multicolumn{1}{|c|}{ Indirect care activities } & No=20 & \% \\
\hline 9 & Finishing records needed for blood and blood product requisition. & 18 & $\mathbf{9 0}$ \\
\hline 10 & Preparing dietary requisition records. & 8 & 40 \\
\hline 11 & Bringing supplies to the department. & 1 & 5 \\
\hline 12 & Distributing supplies to patient rooms. & 9 & 45 \\
\hline 13 & Performing clerical activities. & 17 & $\mathbf{8 5}$ \\
\hline
\end{tabular}

Table (8): Environmental activities performed by the studied assistant nurses as observed by the researcher at Assiut University Hospitals (No=20).

\begin{tabular}{|c|c|c|c|}
\hline & Environmental activities & $\mathrm{No}=20$ & $\%$ \\
\hline 1 & Making bed. & 13 & 65 \\
\hline 2 & Cleaning medication car. & 9 & 45 \\
\hline 3 & Arranging medication car. & 8 & 40 \\
\hline 4 & Clean patient's cupboard. & 9 & 45 \\
\hline 5 & Clean patient beds. & 9 & 45 \\
\hline 6 & Cleaning machines and medical instruments. & 13 & 65 \\
\hline 7 & Cleaning medication refrigerator. & 8 & 40 \\
\hline 8 & Cleaning dressing equipment. & 14 & $\mathbf{7 0}$ \\
\hline 9 & Arranging equipment in the operating room. & 4 & 20 \\
\hline 10 & Cleaning the operating room. & 4 & 20 \\
\hline 11 & Arranging nursing office. & 9 & 45 \\
\hline 12 & Cleaning bottle's for artificial feeding. & 1 & 5 \\
\hline
\end{tabular}

Table (1) : shows the socio-demographic characteristics of the head nurses at Assiut University Hospitals. This table indicates that all of them were females, and that the highest percent of them had a bachelor degree of nursing science and worked at Assuit University Main Hospital (87.5\% and 76.4\%) respectively. Over one third $(38.8 \%)$ were aged from 30 to $<35$ years, having from 5 to $<10$ years of experience, and the mean age of the total study sample was (37) years.

The Socio-demographic characteristics of the studied assistant nurses at Assiut University Hospitals depicted in Table (2) : show that all of them were females. The majority of them had secondary education (diploma), and worked at Assuit University Main Hospital $(100 \%, 77.5 \%$, and $65 \%$ ) respectively . Over one third of them were aged $(20$ to $<25)$ years, and had 3 to $<5$ years of experience $(35 \%, 35 \%)$ respectively.

Table (3) : illustrates the direct care activities performed by the studied assistant nurses as reported by head nurses at Assiut University Hospitals. It shows that a high percentage of the assistant nurses assist during medical examinations, general hygiene for patients and help the nurse in changing patient position $(84.7 \%, 66.7 \%$ and $63.9 \%)$ respectively. There were statistically significant differences among the study sample as regard to the direct care activities performed by the assistant nurses
Table (4) : illustrates the indirect care activities performed by the studied assistant nurses as reported by the head nurses at Assiut University Hospitals. It shows that most of them collect specimens and deliver it to the laboratory, receive test results and keep it in the patient files $(98.6 \%$, and $95.8 \%)$ respectively. The majority of them cut gauze and cotton to prepare sterilized pads, roll the pads for dressing, sent medical instruments for sterilization $(86.1 \%, 86.1 \%$ and $84.7 \%)$ respectively. There were statistically significant differences among the study sample as regard indirect activities.

As evident in table (5) : Environmental activities performed by the studied assistant nurses as reported by the head nurses at Assiut University Hospitals. It shows that most of them $(93 \%)$ help the nurse in making bed correctly. The majority of them clean machines and medical instruments, maintain the cleanliness of the surrounding environment and clean medication cart $(86.1 \%, 83.3 \%$ and $83.3 \%)$ respectively. There were high statistically significant differences among the study sample as regard environmental activities.

Table (6) : Direct care activities performed by the studied assistant nurses as observed by the researcher at Assiut University Hospitals. Most of them (90\%) prepared equipment for taking blood samples from patients, (60\%) of them accompanied the patient during medical requests, and only (5\%) of them 
perform manual Albumin test, insert urinary catheter for children, and prepare bottle feeding.

Indirect care activities performed by the studied assistant nurses as observed by the researcher at Assiut University Hospitals showed in table (7) : All of them $(100 \%)$ prepare dressing for sterilization. Most of them (90\%) collected, labeled, and send the specimens to the laboratory, received test results and keep it in the patient files, checked patient tests for completeness. and finished records needed for blood and blood product requisition. The majority of them (85\%) performed clerical activities, and a low percent of them bring supplies requisition to the department.

Environmental activities performed by the studied assistant nurses as observed by the researcher at Assiut University Hospitals shows in table (8). A high percent of them $(70 \%)$ cleaned surgical equipment. About two thirds of them (65\%) make bed and cleaned machines and medical instruments, and a low percent of them (5\%) sterilized bottles for artificial feeding.

\section{Part (III) Focus Group Discussions}

The third part of results is qualitative data and it will be presented according to the following sequence:

\section{Socio demographic characteristics:}

The total number of the assistant nurses who participated in the focus group discussions was (20). All of them were females, their mean age was (24.3) years old and their mean years of experience was (2.6) years. Regarding to the education level (4) of them were having preparatory education, (15) of them were having secondary education and only one was having Bachelor degree in nursing science. (13) of them were working in the Main Assuit university hospital, (4) of them were working in the Pediatric Assuit university hospital and (3) of them were working in the Woman's Health Hospital.

The assistant nurses in this part of the study had verbalized their experiences regarding their job duties and responsibilities, supervision and the problems they face in their job.

Question one: What are the direct care activities you perform to the patients?

The participants were asked to explain the direct care activities they perform for patients. The majority of them were accompanying the patient during medical requests, half of them were measuring vital signs, giving (oral, suppository or local medication), withdrawal blood samples from patient, giving I.V medications and solutions through cannula and applying bronchodilator inhalation cession.

The minorities of them were assisting in patient bed bath and handling equipment for the nurse, but only one of them was helping the nurse in changing patient positions patients, handling the doctor during changing dressing, handling bedpan for bedridden patients, giving I.M injection, inserting cannula, monitoring blood glucose level, blood samples withdrawal for matching and grouping from patient relatives and giving insulin injection for patients. However, only one of them was feeding the patient by nasogastric tube, making Electrocardiography (ECG) and applying enema.

They said that they perform a lot of nursing care tasks to the patients.

Question two: What are the indirect care activities you perform to the patients?

The participants were asked to explain the indirect care activities they perform. All of them were collecting, labeling, and delivering samples to the laboratory, receiving test results and keeping it in the patient files, finishing blood and blood product requisition records and making clerical activities. All of them said that they perform the messenger activities as going to the laboratory considered the largest duty among the indirect care duties.

About half of them were receiving medication stock with the nurse, prepare dressing for sterilization, distributing supplies to patient rooms and finishing dietary requisition records. The minority of them were bringing supplies requisition to the department. While only one participant was finishing patient admission and discharge records.

Question three: What are the environmental activities you perform to the patients?

The participants were asked to explain the environmental duties they perform. Half of them were cleaning machines as instruments and dressing trays. One quarter of them were cleaning patient beds and patient cupboard. The minority of them were cleaning and arranging medication in the cart. While only one of them was arranging operating rooms.

Question four: Who is responsible for supervising you? The participants were asked to determine who supervise them during work.

Most of them said to the researcher that the head nurse and the staff nurse were the responsible for supervising them, half of them said that the doctor is responsible for supervising them.

Question five: What is the formal and informal training program you received after appointment?

All of them were asked to mention the training program they received after appointment. The majority of them told the researcher that they learned how to perform the department duties from their senior assistant nurses. But two of them told the researcher that they learned the duties by themselves or through the senior staff nurse in the department. There is no formal training program made for us.

Question six: What is your job description? 
The participants were asked about their job description. All participants told the researcher that there is no job description for them and three of them said that they do what the staff orders them to do.

Question seven: What are the skills needed for you at the job?

The participants were asked to explain the skills they need at this job. The majority of the participants wanted to learn skills about ward cleric activities, five of them wanted to learn how to prepare dressing pads for sterilization, three of them wanted to learn basic nursing skills, and steps of finishing blood product requisitions, and only one of them wanted to learn bed making procedure correctly.

Question eight: What are the job related problems you face in your job and how can you solve it?

The majority of the assistant nurses were suffering from conflict, poor communication and bad dealing from all health team, unfair work assignment, poor salaries was considered a big problem among the assistant nurses, and three of them were suffering from unfair disciplinary action, work over load and bias from the supervisors.

To solve these problems thirteen of them explain the reasons of the problem to the supervisor, ten of them keep silent and do not speak about the problem, and four of them solve their problems by using complaint report and two of them apology in case of making mistakes or defend themselves verbally when they face a problem.

Question nine: What are your suggestions for improving your job?

The participants were asked to freely express their suggestions for improvement of their job. All the participants assured the necessity of increasing salary is very important, thirteen of them wanted to enhance relationships with the staff, six of them wanted training programs and job descriptions before appointment, and four of them wanted to have health insurance.

\section{Discussion}

Historically, changes in the healthcare system have led to changes in the numbers and types of personnel who deliver direct care to patients. In response to cost-control initiatives, hospitals have increased the use of unlicensed assistive personnel (UAPs), while few studies in the nursing literature focus on (UAPs), their role and their perceptions of working relationships with RNs (Grant \& Portter, 2004).

The National Council of State Boards of Nursing (NCSBN), (1995) noted that unlicensed assistive personnel are equipped to assist not replace the registered nurse. Nursing is a knowledge-based discipline and cannot be reduced only to a list of tasks. It is essential for the registered nurses to have specialized education, professional judgment and carefulness for providing quality nursing care.

Job analysis is used to establish and document the 'job relatedness' of employment procedures such as training, selection, compensation, and performance appraisal Lingham, (2008), Thereby the creation of job description is the most common use for job analysis Brannick, Levine \& Morgeson, (2007). Usually, job descriptions are created by compiling the most important information gathered in the job analysis, essentially summarize the findings of the job analysis and highlight the most important elements of the job (Royer, 2010).

The majority of the assistant nurses at Assuit University Hospitals were having diploma degree, one quarter of them were having secondary degree, while only one of them was having bachelor degree. This was consistent with the findings of Case, (2004) who found that (UAPs) educational levels vary from less than a high school graduate to those holding advanced degrees. While, Alewa, (2004) found that most hospitals agreed that it is essential for assistant nurses to have high school diploma.

As regards to the main activities performed by the assistant nurses this study included three areas; direct care, indirect care, and environmental duties. This was consistent with the study findings of Spilsbury \& Meyer, (2004) who found that the health care assistants (HCA) job descriptions clearly identified three key areas of work ;direct care, housekeeping and clerical duties. And partially consistent with Alewa, (2004) who classified the activities of the (UANs) into direct care, indirect care and personal activities.

As regards to the direct patient care activities performed by the assistant nurses as reported by the head nurses table(3), it revealed that the assistant nurses perform a supportive role for the patients in the activities of daily livings and help nurses in the duties which need no nursing professionalism, such as nutrition, elimination and patient hygienic care. This finding was congruent with the study findings of Bostrom\& Zimmerman, (1993) and Yoder-Wise, (1999) cited in Alewa, (2004) who assured the same activities performed by the (UAPs) without direct observation from the responsible staff nurse.

Also, majority of them assist during medical examination (handling), and help nurses in changing position for patients this may be due to shortage of the nursing staff, this finding was consistent with the study findings of Conway \& Kearin, (2007) who found that the main role of patient support assistant (PSA) were providing physical assistance to nurses, and medical staff, primarily for manual handling and dealing with heavy or difficult patients.

The majority of them did not empty bed pan or urine bag because they think that these activities are the responsibility of the workers. Also, most of them did 
not assist the patient in taking shower inside the bath room. This may be due to cultural back ground of the patients and the assistant nurses regards bathing in Upper Egypt consider this as breaking of the personal privacy.

As regards to the indirect care activities performed by the assistant nurses and reported by the head nurses Table (4) : most assistant nurses were taken the samples, delivering it to the laboratory, receiving test results and keeping it in the patient files, this is the cure of the assistant nurses job at Assuit university hospitals. This was congruent with the findings of the observed data Table (7) : and the findings of the focus group discussion question (2).

High percent of them did not finish the admission procedure for new patients; this might be done by the patient relatives. Also, they did not finish the patient file and records after death as it is the responsibility of the staff nurse.

As regards to the environmental activities performed by assistant nurses Table (5) : supported by the observed data Table (8) : and the focus group discussion data question (3) which revealed that most assistant nurses were helping in bed making, cleaning machines, and medical instruments. Maintained the cleanliness of the surrounding environment, and cleaning medication cart. This may be due to shortage of the nursing staff.

With this respect New York State Nurses Association, (NYSNA) (2007) mentioned that the assistant nurses cleaning duties was emptying garbage cans, ensuring that a patient has clean sheets and towels, and cleaning the floor. Most of them do not arranging supplies in the unit cupboard, because staff nurse is responsible and accountable about the inventory and supplies against any lose.

The data observed in Table (6) supported by the focus group discussions findings question (1), which revealed that the assistant nurses at Assuit University Hospitals were working without any assigned work plan and minority of them were performing direct nursing activities such as applying bronchodilator cession and oxygen therapy, taking blood samples from patient, inserting cannula, giving medication through cannula, measuring vital signs, measuring blood glucose level, taking blood samples for matching and grouping from patient relatives , giving insulin injection for patients, feed patients by nasogastric tube, making Electrocardiogram (ECG) and applying enema. These performed duties were illegal and harmful because they were nonprofessional personnel. This may be due to shortage of the nursing staff at Assuit University Hospitals, also these activities affect the quality of patient care, and may harm the patients.
With this respect the NYSNA, (2007) stated that there are some activities that cannot be assigned to (UAPs) as performing sterile or invasive procedures or techniques ,inserting urinary catheters, delivering nasogastric tube feedings, administering oxygen, administering medications, or blood or blood products.

With the same respect McLeod, (2001) considered that the typical role of unqualified staff is housekeeping. Also, Spilsbury \& Meyer, (2004) considered (HCAs) are misused when they are asked to monitor blood glucose level, and there are legal implications for the (UAPs) due to the potential risk to patients.

This was consistent with the study findings of Hardie, (1978)\&Thornly, (2000) who found that the role of (UAPs) has been largely unacknowledged and there is lack of understanding of their contribution to patient care. Also, Gordon, (1995) \& ShindulRothchild, (1994) stated that patient safety and the quality of care suffer when (UAPs) replace experienced RNs at the bedside.

While, Roberta et al., (1998) stated that in most settings, the (UAPs) was a multipurpose worker who did both nonclinical and clinical tasks. Frequently the clinical tasks included drawing blood, performing electrocardiograms, and sometimes changing dressings, administering treatments, and implanting catheters. UAPs were seen in a more positive light when their work was restricted to nonclinical and noninvasive patient care tasks.

From the focus group discussion results about who is responsible for giving the assistant nurses instructions and supervising them. Most of the assistant nurses said that head nurses and staff nurses are supervising and giving them instructions, but half of them said that the medical staff with the head nurses and staff nurses supervising and giving them instructions.

With this respect Alewa, (2004) stated that (UANs) have no direct contact with medical staff and they get instruction by head nurses and staff nurses, also Spilsbury \& Meyer, (2004) mentioned that the most significant control of the health care assistants (HCAs) work was exerted by the registered nurse at the ward level.

As noted in the focus group discussions, there is no training program or orientation made for the assistant nurses and there is no job description for them at the hospitals. Also, most of the head nurses said that Table (3) there is no need for the assistant nurses to take training course in nursing profession, the principles of effective communication or infection control. This was congruent with the study findings of Barter \& Furmidge, (1994), Manuel \& Alster, (1994) who found that there are no national guidelines for defining the scope of (UAPs) practice 
or for the development, implementation, and evaluation of training programs, many of which are deemed totally inadequate for preparing (UAPs) to assume expected duties.ed

Conversely, Roberta et al., (1998) found that training programs for the (UAPs) anywhere ranged from several weeks to a month or more, and many nurses found the limited training was inadequate for the duties (UAPs) were supposed to carry out.

With this respect Synder et al., (2004) mentioned that hospitals and other healthcare agencies are ultimately responsible for the orientation and training of an (UAPs). "The hiring of UAPs increases the responsibility for orientation and training of these individuals because at this time, no community standards for content of training programs exist for these workers". The task that can be done by the (UAPs) should be included in the written job description and assessed annually during performance evaluations.

Also, assistant nurses reported in the focus group discussions that they gained skills and knowledge about their work through experience, by the instructions from their senior colleagues and nursing staff. This finding was consistent with the findings of the study of Spilsbury \& Meyer (2004) who found that health care assistants (HCAs) gained skills and knowledge about their work through experience of working in clinical specialty.

In this respect Alewa, (2004) mentioned that nurses retain accountability for the delegation and for adequate supervision of the delegated activity to the (HCAs).

The findings of question (7) of the focus group discussions revealed that a minority of the assistant nurses wanted to learn basic nursing skills and how to prepare dressing pads for sterilization. While, the majority of them wanted to learn skills for clerical work of medical investigations. With this respect Vail et al., (2010) found that many health care assistants had the desire to be trained as a nurse.

The focus group discussion question (8) revealed that the majority of the assistant nurses were suffering from poor communication, bad dealing of all hospital staff and unfair work assignment. While, minority of them was suffering from unfair disciplinary action, work overloads and bias of the supervisors. This is in contrast with the study findings of Vail et al., (2010) who revealed that the health care assistants felt accepted and supported by health team members and valued the support that they were receiving. And they enjoyed their work, and particularly appreciated the patient contact and positive feedback gained.

With this respect Conway \& Kearin, (2007) reported that challenges voiced by patient support assistants
(PSAs) included work overload and being expected to achieve both allocated cleaning tasks and provide patient support, being requested to assist with aggressive patients and working with other (PSAs).

Also, a poor salary was considered a large problem among the assistant nurses. This was supported by the study of Vail et al., (2010) who found that the key sources of frustration among health care assistants included poor salary.

\section{Conclusions}

In the light of the findings of the present study, the following conclusions can be drawn

1. All assistant nurses at Assiut University Hospitals were females, the majority of them having secondary education (diploma), aged between $(20$ to $<30)$ years old, and having from 3 to $<5$ years of experience.

2. There is no training program or orientation made for assistant nurses and there is no job description for them at the Assuit University Hospitals.

3. Assistant nurses at Assuit University Hospitals work without any assigned work plan and sometimes perform nursing activities which need nursing profession such as (applying bronchodilator cession and oxygen therapy, taking blood samples from patient, inserting cannula, giving medication through cannula, measuring vital signs, measuring blood glucose level and so on).

4. There was congruency between head nurses' opinions, job analysis and the focus group discussion as regards indirect care, and environmental activities performed by assistant nurses.

5. The findings of the job analysis and the focus group discussion were congruent as regards the direct care activities performed by assistant nurses, but these findings were incongruent with the head nurses' opinion.

6. Poor communication, bad treatment of all hospital staff, poor salaries and unfair work assignment were considered the main problems reported by assistant nurses.

\section{Recommendations}

Based on the results of the present study, the researcher suggested the following recommendations

1. Standardized educational qualifications (at least average education) for assistant nurses should be established.

2. Conducting training programs for assistant nurses about infection control principles, communication skills, and nursing profession. 
3. Constant direct supervision by the superiors of assistant nurses should be established in the hospitals.

4. Informing head nurses, physicians, and staff nurses who are supervising the assistant nurses of the duties and responsibilities of assistant nurses.

5. Dealing with the problems facing assistant nurses.

6. Authoritative agreement to apply the developed job description for assistant nurses at Assuit University Hospitals.

Job Description for Assistant Nurses at Assuit University Hospitals

Job title: Assistant Nurse.

Department: Assuit University Hospitals

Departments.

Date: 00/00/0000

Supervisor: Supervised by the head nurse and staff nurse in the department.

Job summary: Perform non-nursing activities that are directly or indirectly related to the patients and environmental duties in the department.

Position requirements:

Qualifications:

1- Education :Diploma of Secondary Technical Schools.

\section{2-Training courses}

Training courses in infection control.

Training course in nursing profession knowledge.

Training courses in effective communication skills.

Duties and responsibilities

\section{I-Direct patient care duties}

1. Accompany the patients to go to other departments.

2. Help patients to walk within the department.

3. Help patients to move outside the department.

4. Help the nurse in changing the patient's position.

5. Assist in maintaining the patient's personal hygiene .

6. Assist in patient bed bath.

7. Assist in patient bath inside the bathroom.

8. Handle the bedpan for bed-ridden patients.

9. Empty the bedpan.

10. Empty the urine bag.

11. Determine urine volume in the urine bag.

12. Implement preparatory enema.

13. Assist during medical examinations of the patients. (Such as handling things during the examination).

14. Help in preparing patients for operations.

15. Measure the weight of patients.

16. Measure the height of patients.

17. Help in patient feeding.

18. Make cold compresses for feverish patients.
19. Help the head nurse, the physician and the nurse in performing urinary catheterization procedure.

II-Indirect patient care duties

1. Send medical instruments for sterilization.

2. Bring medical instruments to the department after sterilization.

3. Cut gauze and cotton to prepare dressing.

4. Roll the pads for dressing sterilization.

5. Collect the specimens and delivering them to the laboratory.

6. Receive test results and keep them in the patient files.

7. Bring medication requisitions with the nurse.

8. Deliver and receive correspondence to and from the department.

9. Finish patient admission requirements.

10. Finish the patient's file and records after death.

11. Finish the records of the nursing team vacations.

12. Deliver patients' files to the census office.

13. Answer the department telephone calls.

III-Environmental care duties

1. Help the nurse in making bed correctly.

2. Maintain the cleanliness of the surrounding environment.

3. Arrange patients' rooms.

4. Clean patients' cupboards.

5. Clean patients' beds.

6. Clean machines and medical instruments.

7. Clean the medication cart.

8. Arrange the medication cart

9. Clean the dressing cart.

10. Arrange the dressing cart.

11. Arrange supplies in the cupboard.

\section{References}

1. Alewa A., (2004) : Situational Analysis of Employing Unlicensed Assistive Personnel in Selected Intensive Care Units in New Kaser ElAini Teaching Hospital. Unpublished Master Thesis. Faculty of Nursing. Cairo University.

2. Barter M., Furmidge M., (1994) : Unlicensed Assistive Personnel: Issues Relating to Delegation and Supervision. Journal of Nursing Administration 24(4); 36-40.

3. Bostrom J., \& Zimmerman J., (1993): Restructuring Nursing for Competitive Health Care Environment. Nurse Economic \$, 11(1); 35-54. Cited by Alewa A., (2004): Situational Analysis of Employing Unlicensed Assistive Personnel in Selected Intensive Care Units in New Kaser El-Aini Teaching Hospital. Unpublished Master Thesis. Faculty of Nursing. Cairo University.

4. Brannick M., Levine E., \&Morgeson F., (2007) : Job and Work Analysis: Methods, 
Research and Applications for Human Resource Management. Thousand Oaks, CA: Sage Publication

5. Case B., (2004): Delegation skills. Advance for Nurses, 1(3); 20-26.

6. Conway J., Kearin M., (2007) : The contribution of the Patient Support Assistant to direct patient care: An exploration of nursing and PSA role perceptions. Contemporary Nurse: Vol. 24, Nurse Recruitment \& Retention, pp. 175188.

7. Darbyshire B., (1969): Guide to The Study of Activities of Health Personnel in Hospital (WHO project India D 223).New Delhi.

8. Gordon S., (1995): Voices from the frontlines: Nurses speak out! Revolution-The Journal of Nurse Empowerment, 5(1); 24-30, 66.

9. Grant E., \& Potter p., (2004): Understanding RN and Unlicensed Assistive Personnel Working Relationships in Designing Care Delivery Strategies, Journal of Nursing Administration 34(1); 19-25.

10. Hardie M., (1978): The international background: United Kingdom. In Nursing Auxiliaries in Health Care (M. Hardie \&L.Hockeyeds), pp. 130- 131. Croom Helm, London, UK.

11. Houser J., (2003): A Model for Evaluating the Context of Nursing Care Delivery. Journal of Nursing Administration, (JONA). (33); 39-47.

12. Human Resources (HR) Guide (2009) : Job Analysis: Job Descriptions.http://www.hrguide.com/jobanalysis.htm

13. Huge P., (2004): Patient Safety and Quality of Care: The Role of the Health Care Assistant". Journal of Nursing Management.12 (6); 452-459.

14. Jack B., Brown J., \& Chapman T., (2004): Word Managers Perceptions of Role of Health Care Assistants. British Journal of Nursing 13 (5); 270-275.

15. Lingham L., (2008): Human Resources/Standard Job analysis process, The New York Times Company. http://en.allexperts.com/q/Human-Resources2866/2008/7/Standard-Job-analysis-process.htm

16. http://www.managementstudyguide.com(2012), $\mathrm{http} / / / \mathrm{www} \cdot \mathrm{managementstudyguide.com/job-}$ analysis.htm ,http://www.managementstudyguide.com/jobdes criptionspecifican.m

17. Manuel R., \& Alster K., (1994): Unlicensed personnel: No cure for an Ailing Health Care System. Nursing \& Health Care, 15; 18-21.

18. McLeod A., (2001): Support role spreads the workload in intensive care. Nursing times, 97(29); 40-41.
19. Ministry of Health, (2009): Egyptian Health Insurance assistant nurses job description.(unpublished)

20. National Council of State Boards of Nursing (NCSBN). (1995): Delegation concepts and decision-making process. Council position paper, 1995.

http://www.ncsbn.org/regulation/uap_delegation documents_delegation.asp[Context Link]

21. New York State Nurses Association (NYSNA), (2007) : Guidelines Regarding Utilization of Licensed Nurses (RNs and LPNs) and Unlicensed Assistive Personnel (UAP) in the Delivery of Nursing Care; 1-9.

22. Roberta M., Garland D., Hara M., \& Perfetto L., (1998) : Caught in the Cross fire of Change: Nurses' Experience with Unlicensed Assistive Personnel. Applied Nursing Research 11(3); 101-110.

23. Royer K., (2010) : Job descriptions and job analyses in practice: How research and application differ. College of Liberal Arts and Social Sciences .Department of Psychology. Chicago, IL, DePaul University. Doctor of Philosophy.

24. Shindul-Rothchild J., (1994): Restructuring, redesign, rationing, and nurse's morale: A qualitative study on the impact of competitive financing. Journal of Emergency Nursing, 20; 497-504.

25. Snyder D., Medina J., Bell L., \& Ann wavra T., (2004): American association of critical care nurses (AACN) Delegation Handbook", $2^{\text {nd }}$ Edition, Pp1-12.

26. Spilsbury K., \& Meyer J., (2004): Use, Misuse and Non-use of Health Care Assistants: understanding the work of health care assistants in a hospital setting. Journal of Nursing Management, 12(6); 411-418.

27. Vail L., Bosley S., Petrova M., \& Dale J., (2010): Healthcare assistants in general practice: a qualitative study of their experiences, Health Sciences Research Institute; 1-13.

28. Yoder-Wise P., (1999): Leadership Roles and Management in Nursing. $2^{\text {nd }}$ ed. Pp.366-383.cited by Alewa A., (2004): Situational Analysis of Employing Unlicensed Assistive Personnel in Selected Intensive Care Units in New Kaser ElAini Teaching Hospital Unpublished Master Thesis. Faculty of Nursing. Cairo University.

29. Williams J. (2012): Importance of Job Analysis \& Job Descriptions".

http://www.ehow.com/about_5388138_importan ce-job-analysis-job-descriptions.html 